\title{
Correction to: Effects of long-term vitamin $D$ and $n-3$ fatty acid supplementation on inflammatory and cardiac biomarkers in patients with type 2 diabetes: secondary analyses from a randomised controlled trial
}

\author{
Christine P. Limonte ${ }^{1,2}$ (D) Leila R. Zelnick $^{1,2}$ (D) John Ruzinski ${ }^{2} \cdot$ Andrew N. Hoofnagle $^{1,3}$ (D) Ravi Thadhani $^{4}$ (D) \\ Michal L. Melamed ${ }^{5}$ (D) I-Min Lee ${ }^{6,7}$ (D) - Julie E. Buring ${ }^{6,7}$ (D) - Howard D. Sesso ${ }^{6,7}$ (D) JoAnn E. Manson ${ }^{6,7}$ (D) \\ Ian H. de Boer ${ }^{1,2,8}$ \\ Published online: 10 December 2020 \\ (C) Springer-Verlag GmbH Germany, part of Springer Nature 2020 \\ Correction to: Diabetologia \\ https://doi.org/10.1007/s00125-020-05300-7
}

The graphical abstract (available at https://doi.org/10.1007/ s00125-020-05300-7) included a typographical error (1000 g $n-3$ fatty acid supplementation, rather than $1000 \mathrm{mg}$ ). This has now been corrected.

Publisher's note Springer Nature remains neutral with regard to jurisdictional claims in published maps and institutional affiliations.

The online version of the original article can be found at https://doi.org/ 10.1007/s00125-020-05300-7

Christine P. Limonte

climonte@uw.edu

1 Division of Nephrology, Department of Medicine, University of Washington, Seattle, WA, USA

2 Kidney Research Institute, University of Washington, Seattle, WA, USA

3 Department of Laboratory Medicine, University of Washington, Seattle, WA, USA

4 Office of the Chief Academic Officer, Partners HealthCare, Boston, MA, USA

5 Division of Nephrology, Department of Medicine, Albert Einstein College of Medicine, Bronx, NY, USA

6 Division of Preventive Medicine, Brigham and Women's Hospital, Harvard Medical School, Boston, MA, USA

7 Department of Epidemiology, Harvard T.H. Chan School of Public Health, Boston, MA, USA

8 Puget Sound VA Healthcare System, Seattle, WA, USA 